\section{SENTIDOS DE LUGAR E DE TOPOFILIA}

Lívia de Oliveira

Estoy mirando, oyendo Con la mitad del alma en el mar Y la mitad del alma en la tierra $Y$ con las dos mitades del alma miro el mundo.

Pablo Neruda

Com as palavras de Neruda, também olho contemplando e ouço perscrutando o mundo todo, por terra, mar e ar, com as duas metades da minha alma. A metade da experiência e a outra metade da vivência, sempre mergulhadas no néctar da Geografia. Sempre alimentadas pelas cores das montanhas e das planícies, pelos aromas das florestas e dos cerrados, pelos sabores significantes das cidades e dos campos, pela vibração e transparência dos ventos, das nuvens e dos ares, pela fluidez das aguas dos rios e dos mares, pelo brilho e beleza das flores e dos frutos, pelas texturas culturais e humanistas, pelo encanto telúrico dos bichos e animais, enfim pelos sentimentos e afeição das pessoas e das gentes.

As duas metades da minha alma se entrelaçam, aqui e agora, nesta mesa redonda, com a incumbência de dirigir algumas palavras. Palavras estas sobre os sentidos de lugar e de topofilia.

A descoberta das ideias e a tradução destas duas obras deYi-FuTuan - "Topofilia" (2012) e "Espaço e Lugar" (1983) - me lançaram de chofre num mundo topofílico, telúrico, afetivo, de pausas e de movimentos.

Professora Emérita do Instituto de Geociências e Ciências Exatas da Universidade Estadual Paulista (IGCE/UNESP), campus de Rio Claro.

liviadeoliveira@yahoo.com.br.

$\triangle$ Rua Quatro, 1229, apto. 101, Rio Claro, SP. 13500-970.

Geograficidade | v.3, n.2, Inverno 2013

ISSN 2238-0205
Quanto à topofilia, o autor acrescenta um subtítulo abrangente: um estudo da percepção, atitudes e valores do meio ambiente. São estes conceitos que enriquecem e ampliam a noção de meio ambiente, colocando-a diante da visão de mundo, no contexto da experiência. O neologismo topofilia entrou para o dicionário, traduzindo o "elo afetivo", entre nós e a natureza.

A percepção é colocada no cerne das preocupações geográficas, chamando a atenção para a relevância dos sentidos dos homens, suas sensações e seus sentimentos, seus sonhos e seus anseios. Mostra, também, que a percepção é ação e é um estender-se para o mundo; é uma linguagem de sinais e de símbolos. Os sensores táteis, as mãos competentes permitem perceber asperezas e as texturas, porém são os visuais que nos fornecem a tridimensionalidade do nosso meio ambiente, as cores e a distribuição dos objetos, ensejando a movimentação espacial.

Por outro lado, as atitudes diante do meio ambiente, são reveladas as preferências de idade e de gênero, as posturas éticas, as condutas individuais e/ou coletivas. Como o estrangeiro é visto pelo nativo ou vice-versa. As atitudes podem ser ambíguas ou transparentes, as convivências podem ser preconceituosas ou ingênuas e as afetividades podem ser positivas ou negativas. Gostar ou não gostar desta ou daquela pessoa, aceitar ter nascido aqui e não acolá, apreciar as artes reconhecendo a estética e a ética da natureza, sentir prazer no contato com o meio ambiente natural e/ou construído.

As atitudes podem ser premeditadas, presas às aparências em relação ao meio ambiente natural e selvagem, que simbolizam a pureza ou o caos, onde habitam os gênios do mal. Quanto ao meio construído a relação é idílica, alegórica e libertária. Porém, atualmente, tem ocorrido uma inversão: o selvagem representa a ordem ecológica e a liberdade, enquanto a cidade é olhada com cores escuras e sentida 
como caótica e repulsiva. Assim, o autor discute as atitudes destes equívocos e de incertezas em relação a sociedade industrializada, urbanizada, poluída, mas sempre atraindo cada vez mais as pessoas a morarem em cidades.

O valor atribuído ao meio ambiente está acoplado ao interesse e à necessidade. Pois, a humanidade para viver e sobreviver precisa sentir algum valor em seu mundo. A formação e natureza dos valores são engendrados na cultura, no meio ambiente revestido pela afetividade topofílica. Estilos de vida e classes sociais determinam em parte a preferência e escolha de ambientes valorizados pela educação, pelo nível de vida, pelo poder aquisitivo, quer individual ou coletivamente.

Os valores do meio ambiente podem ser geográficos: viver no campo ou na cidade. Os valores do campo residem numa imagem ideal de vida, ligados à natureza e à saúde física e mental. Ao passo que os valores da cidade estão mais voltados à vida cultural e artística e nas possibilidades socioeconômicas. Entre estes dois valores se interpõem a cidade pequena, na qual a vida corre mais lenta, mais tranquila para melhor criar os filhos e dispor de jardins floridos, gramados, animais de estimação.

Modernamente, foi introduzido o viver em condomínio, quer em casas como em apartamentos. As famílias valorizam este estilo de vida pela segurança, ambiente saudável, ar puro, sem ruídos estridentes e relativamente próximos a tudo aquilo que é valorizado numa cidade grande. Assim as diversas classes sociais procuram atender suas necessidades e seus interesses buscando o valor atribuído ao meio ambiente para suas vivências.

Ainda, segundo Tuan (2012), os significados de percepção, de atitudes e de valores se superpõem e, se tornam claros dentro do propósito expresso em cada um desses processos. Considera que a atitude assumida, frente ao mundo, é formada por longa sucessão de percepções e de experiências. As atitudes adotadas pelas pessoas para com o meio ambiente espelham seus interesses e seus valores, e refletem sua visão de mundo. Trata-se de uma experiência conceitualizada, parcialmente pessoal e, em grande parte, social.

Sabe-se que os fatores culturais e o meio ambiente físico interferem na visão de mundo. Os conceitos cultura e meio ambiente se superpõem, do mesmo modo que os conceitos homem e natureza, constituindo um todo. Para se conhecer a preferência ambiental de uma pessoa, mister é examinar sua herança biológica, sua educação, seu trabalho e seus arredores físicos.

A ideia de que cada indivíduo estrutura seu espaço geográfico em torno de si próprio, parece universal. Os seres humanos, individualmente ou em grupo, tendem a estruturar o mundo tendo o self como o centro. Com isso, o mundo se orienta por uma série de valores irradiados da própria pessoa ou de seu grupo.

Quanto ao "Espaço e Lugar" (1983), Tuan incorpora um subtítulo: A perspectiva da experiência. Este acréscimo amplia com muita propriedade, assinalando os rumos da obra.

O autor indaga: que é espaço? Que é lugar? Para responder estas questões os conceitos se fundem e se diferenciam apenas por um continuum, assim "quando o espaço nos é familiar, torna-se lugar". A perspectiva da experiência é que permite isolar os conceitos, que na realidade constituem uma moeda, com dois lados. Espaço e lugar são essencialmente, inseparáveis e permeiam nossas percepções, nossas atitudes e nossos valores de visão de mundo.

Por exemplo, a cidade é um lugar ao mesmo tempo um espaço, dependendo da escala, dos sentimentos e das ideias que se relacionam e se imbricam formando um todo. Dependendo da faixa etária, lugar e espaço se diferenciam, entre as crianças, adolescentes e adultos. $O$ mesmo acontece com os gêneros: para mulheres e para os homens 
espaço e lugar são experienciados de maneiras diversas, permeados pelos sonhos, pelos símbolos e pelos imaginários.

Os conceitos de espaço e de lugar estão sempre submetidos às transformações da sociedade; sempre recebendo novas informações e aceitando ou não as atuais mudanças.

A dimensão tempo está implícita em todos os lugares quer nas ideias de liberdade, movimento, querno esforço em procura da acessibilidade. Assim, também a dimensão temporal está na experiência do espaço, confundindo-se facilmente às essências espacial e temporal. $\mathrm{Na}$ construção do nosso espaciotemporal vivenciamos meios ambientes naturais e construídos, e sabemos que os grupos culturais se distinguem na maneira de perceber e de organizar seus espaços e seus lugares. Isto é constatado através dos tempos e dos espaços, nos agrupamentos ou nas divergências, na localização em montanhas, ou nos vales, junto aos litorais ou em ilhas. O resultante do mosaico geográfico e histórica da vida humana sobre a superfície terrestre está aí, para ser estudado, explicado ou aceitado, e principalmente compreendido. A literatura contribui para o conhecimento e a apreciação de lugares e para a representação de espaço míticos, simbólicos ou afetivos, que passariam despercebidos, se não forem chamados a nossa atenção, tornando-os visíveis esteticamente.

Estarno mundo, viver no planetaTerra, nascerneste país, morarnesta cidade, estudar nesta escola implicam sentir-se em casa, familiarizado com o nosso "lugar", incrustado no nosso "espaço". É estar "orientado no espaço e sentir-se à vontade em um lugar". É experienciar a alegria de acordar e de dormir em uma cama confortável, comer uma refeição quentinha, mesa, sonhar acordado e fantasiar dormindo.

É a experiência trazida pela perspectiva que as obras emblemáticas de Yi-Fu Tuan nos vaticinam novas aberturas, de novos caminhos e de novas buscas, trazidas no bojo da Geografia Humanista Cultural.
Termino com as palavras de Neruda:

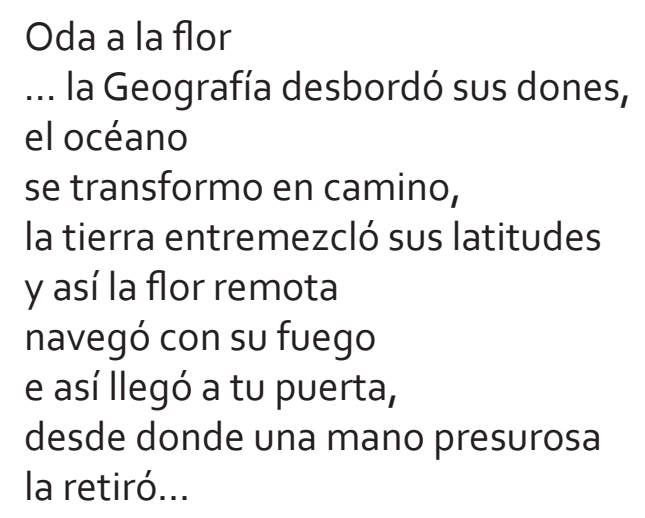

\section{REFERÊNCIAS}

NERUDA, Pablo. Residencia en la tierra. (Selección.) Santiago: Editorial Nascimento, 1953. 381p.

TUAN, Yu-Fu. Espaço e lugar: a perspectiva da experiência. (Trad. Lívia de Oliveira) São Paulo: Difel, 1983. 249p.

Topofilia: um estudo da percepção, atitudes e valores do meio ambiente. (Trad. de Lívia de Oliveira) Londrina: EDUEL, 2012. 342p. 